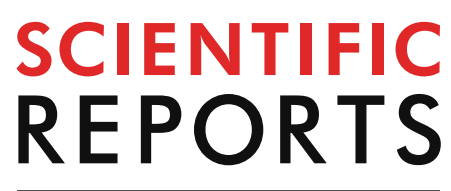

natureresearch

Check for updates

\title{
Polyaniline/Ag nanoparticles/ graphene oxide nanocomposite fluorescent sensor for recognition of chromium (VI) ions
}

\author{
Shaker Ebrahim ${ }^{1}$, Azza Shokry ${ }^{2 \rrbracket}$, M. M. A. Khali| ${ }^{3}$, Hesham Ibrahim ${ }^{2}$ \& Moataz Soliman ${ }^{1}$
}

Selective determination of toxic hexavalent chromium $(\mathrm{Cr}(\mathrm{VI}))$ is a stringent important due to its huge negative impact on the health and environment. Recently, the high sensitivity, rapidness, and costeffectiveness of the fluorescent sensors for $\mathrm{Cr}(\mathrm{VI})$ have been developed. A fluorescent nanocomposite (NC) has been synthesized based on doped polyaniline (PANI), 2-acrylamido-2-methylpropanesulfonic acid (AMPSA) capped Ag nanoparticles (NPs) and graphene oxide (GO) quantum dots (ODs) via in situ reaction for highly selective sensing of $\mathrm{Cr}(\mathrm{VI})$ ions based on the luminescent quenching in the range from 0.01 to $7.5 \mathrm{mg} / \mathrm{L}$. This NC showed an emission peak at $348 \mathrm{~nm}$ with a linear range from 0.01 to $0.05 \mathrm{mg} / \mathrm{L}$ and the low limit of detection (LOD) was $0.0065 \mathrm{mg} / \mathrm{L}(\sim 6 \mu \mathrm{g} / \mathrm{L}$ ). PANI/Ag (AMPSA) GO ODs NC displayed high selectivity for $\mathrm{Cr}(\mathrm{VI})$ over other common metal ions. Notably, the PANI/Ag (AMPSA) GO QDs NC can be used for distinguishing $\mathrm{Cr}(\mathrm{VI})$ and $\mathrm{Cr}(\mathrm{III})$ in solutions. The sensitive determination of $\mathrm{Cr}(\mathrm{VI})$ in real surface water samples was also confirmed and demonstrated recoveries in the range 95.3-99.2\%. This NC will emerge as a new class of fluorescence materials that could be suitable for practical applications.

Monitoring and detection of toxic heavy metal ions are in urgent demand due to their potential highly carcinogenicity mutagenicity ${ }^{1}$. In the aquatic environments, chromium exists as $\mathrm{Cr}$ (III) and $\mathrm{Cr}(\mathrm{VI})$ oxidation states. $\mathrm{Cr}(\mathrm{VI})$ is very harmful due to its high carcinogenic and mutagenic properties while $\mathrm{Cr}(\mathrm{III})$ is harmless and safe ${ }^{2}$. The permissible limit of $\mathrm{Cr}(\mathrm{VI})$ in drinking water was set as $50 \mu \mathrm{g} / \mathrm{L}$ according to the World Health Organization (WHO) report ${ }^{3}$. Therefore, the ability of selectively detection of $\mathrm{Cr}(\mathrm{VI})$ without the interference of $\mathrm{Cr}$ (III) is very important for the human health and environment impact assessments. There are different techniques commonly used for the detection and sensing of $\mathrm{Cr}$ such as the ion chromatography (IC) ${ }^{4}$, inductively coupled plasma mass spectrometry (ICP-MS $)^{5}$ and atomic absorption-emission spectroscopy ${ }^{6,7}$. Eaton et al. have revealed significant ambivalences between the results obtained by these techniques ${ }^{8}$. They analyzed the concentrations of both $\mathrm{Cr}(\mathrm{VI})$ and total $\mathrm{Cr}$ over 1,500 water samples. They found that in almost half of analyzed samples, the determined $\mathrm{Cr}(\mathrm{VI})$ concentrations by the IC were higher than the total Cr concentrations determined by ICP-MS which indicate deficiencies in the discrimination between $\mathrm{Cr}(\mathrm{VI})$ and $\mathrm{Cr}$ (III) ions of these commonly used methods. Therefore, there is a growing demand to develop reliable analytical techniques for selective and accurate $\mathrm{Cr}(\mathrm{VI})$ determination.

The new fluorescent technique presents different advantages such as high sensitivity, fast response time, visualization and high selectivity 9 . High luminescent advanced materials such as porous organic polymers, nanoparticles and carbon dots have been explored to sense $\mathrm{Cr}(\mathrm{VI})^{10-12}$. Although good performance has been obtained, these advanced materials suffered from low sensitivity and low stability 9 . So, the potential materials with excellent stability for sensitive detection and highly selective of $\mathrm{Cr}(\mathrm{VI})$ ions are still challenging and desperately required in the perspective of health issues and environmental protection. Lately, carbonaceous hydride materials have attracted immense attention because of their particular aspects such as monitoring in real-time,

\footnotetext{
${ }^{1}$ Department of Materials Science, Institute of Graduate Studies and Research, Alexandria University, P.O. Box 832, Alexandria, Egypt. ${ }^{2}$ Department of Environmental Studies, Institute of Graduate Studies and Research, Alexandria University, P.O. Box 832, Alexandria, Egypt. ${ }^{3}$ Department of Nanotechnology and Composite Materials, Institute of New Materials and Advanced Technology, City of Scientific Research and Technological Applications (SRTA- City), New Borg El Arab City, P.O. Box 21934, Alexandria, Egypt. ${ }^{\circledR}$ email: azzashokry@alexu.edu.eg
} 
high sensitivity and quick response. Thus, the luminescent hydride NPs have been synthesized as sensors for the detection of $\mathrm{Cr}(\mathrm{VI})$ ions ${ }^{9}$. Recently, we have reported the synthesis and characterization of a novel highly luminescent PANI/Ag (AMPSA)/ GO QDs NC ${ }^{13}$. It was proposed that the interaction between Ag (AMPSA) NPs and PANI by the functional groups on the surface to facilitate the adsorption process. GO QDs are interacted strongly with PANI/Ag (AMPSA) NC via electrostatic interaction. Moreover, there are several studies reported the interaction mechanisms of graphene or GO within the hydride materials ${ }^{14-17}$.

The objective of this work is to use the high fluorescence property of this NC to determine the linearity, sensitivity, dynamic range and the detection limit of $\mathrm{Cr}(\mathrm{VI})$ in the range from $0.01 \mathrm{mg} / \mathrm{L}$ to $7.5 \mathrm{mg} / \mathrm{L}$. The selectivity and interference of PANI/Ag (AMPSA)/GO QDs NC in presence of different metals ions are investigated. The influence of $\mathrm{pH}$ on the PL intensity and on the quenching efficiency of PANI/Ag (AMPSA)/ GO QDs NC is studied in the range of $2-10$. The possible mechanisms for the interaction between PANI/Ag (AMPSA)/GO QDs NC and $\mathrm{Cr}(\mathrm{VI})$ also discussed.

\section{Materials and methods}

Preparation and characterization techniques. Ag (AMPSA) NPs were synthesized by the chemical reduction of silver nitrate using sodium borohydride as a reducing agent. GO QDs were prepared by glucose pyrolysis and dodecylbenzene sulfonic acid doped PANI was prepared by chemical oxidative polymerization method, respectively. In addition, PANI/Ag (AMPSA)/GO QDs NC was prepared by in situ oxidative polymerization of aniline in presence of the nanoparticles. All details regarding the synthesis and characterization of PANI/Ag (AMPSA)/ GO QDs NC and its related materials in the present study can be found in our recent publication $^{13}$.

Detection of $\mathrm{Cr}(\mathrm{VI})$ using luminescence spectra. A stock solution of $100 \mathrm{mg} / \mathrm{L}$ of $\mathrm{Cr}(\mathrm{VI})$ was prepared by dissolving potassium dichromate $(0.0283 \mathrm{~g})$ in $100 \mathrm{~mL}$ of deionized water. The detection of $\mathrm{Cr}(\mathrm{VI})$ was performed at room temperature and $\mathrm{pH}$ 6. The sensing experiments of $\mathrm{Cr}(\mathrm{VI})$ were carried out by monitoring the PL behavior of the PANI/Ag (AMPSA)/GO QDs NC solution. Briefly, series of concentrations of $\mathrm{Cr}(\mathrm{VI})$ $(0-7.5 \mathrm{mg} / \mathrm{L})$ were prepared. The following was added sequentially to a Falcon $15 \mathrm{~mL}$ conical centrifuge tubes: $2 \mathrm{~mL}$ of deionized water followed by the addition of a certain concentration of $\mathrm{Cr}(\mathrm{VI})$ ions. The $\mathrm{pH}$ of this solution was adjusted to 6 using $0.1 \mathrm{M}$ of $\mathrm{NaOH}$ and $\mathrm{HCl}$ then diluted with deionized water to a volume of $3 \mathrm{~mL}$. Finally, a volume of $100 \mu \mathrm{L}$ of PANI/Ag (AMPSA)/GO QDs NC solution was mixed with Cr(VI) solution. The solution was mixed using a vortex mixer and was incubated for $10 \mathrm{~min}$. The PL spectra of the resulting solutions were recorded by the excitation wavelength at $270 \mathrm{~nm}(\lambda \mathrm{ex}=270 \mathrm{~nm})$ and the emission data were collected in the range of 290-500 $\mathrm{nm}$. The maximum fluorescence intensity obtained at $348 \mathrm{~nm}$ was used for the quantification of $\mathrm{Cr}(\mathrm{VI})$. For analytical parameters optimization, the slope of calibration curve was used based on Eq. $(1)^{18}$ :

$$
\left(F_{0}-F\right) / F_{0}=a C_{C r(V I)}+b
$$

where $\mathrm{F}_{0}$ and $\mathrm{F}$ represent the PL intensities of PANI/Ag (AMPSA)/GO QDs in the absence and presence of $\mathrm{Cr}(\mathrm{VI})$ ions, respectively and $\mathrm{C}_{\mathrm{Cr}(\mathrm{VI})}$ is the concentration of chromium $(\mathrm{mg} / \mathrm{L})$. The slope and the intercept of the calibration curve are represented by $a$ and $b$, respectively. The detection limit (DL) can be estimated from the equation of $\mathrm{DL}=3 \mathrm{SD} /$ slope, where $\mathrm{SD}$ is the standard deviation of the calibration curve ${ }^{19}$. The quenching efficiency (QE) was calculated using Eq. $(2)^{20}$ :

$$
Q E=\left(F_{0}-F\right) / F_{0}
$$

For optimization of experimental detection conditions, the effects of different parameters such as $\mathrm{pH}$ and the reaction time between PANI/Ag (ANPSA)/GO QDs NC and Cr(VI) were investigated. In addition, selectivity of PANI/Ag (AMPSA)/GO QDs toward Cr(VI) and the potential of interference with other ions including Fe(III), $\mathrm{Mg}(\mathrm{II}), \mathrm{Pb}(\mathrm{II}), \mathrm{Cu}(\mathrm{II}), \mathrm{Zn}(\mathrm{II}), \mathrm{K}(\mathrm{I}), \mathrm{Cd}(\mathrm{II}), \mathrm{Ni}(\mathrm{II}), \mathrm{Cr}(\mathrm{III}), \mathrm{Na}(\mathrm{I})$ and $\mathrm{Al}(\mathrm{III})$ were also examined.

Detection of $\mathrm{Cr}(\mathrm{VI})$ in water samples. The feasibility of the proposed method for practical applications was investigated in the determination of $\mathrm{Cr}(\mathrm{VI})$ in two water samples (tap water and raw water obtained from drinking water canal, Alexandria, Egypt). The raw water was filtered to remove the impurities. All the $\mathrm{pH}$ of the sample was adjusted as 6 . For validation purpose, the two water samples were analyzed by applying the standard colorimetric method using 1,5-diphenylcarbazide (DPC) ${ }^{21}$. Then, adding $5 \mathrm{mg} / \mathrm{L}$ of Cr(VI) into the samples and measuring the $\mathrm{Cr}(\mathrm{VI})$ concentrations again. The recovery percentages were also determined.

\section{Results and discussion}

Characterization. The structure, crystallinity and morphological properties of this NC were characterized and discussed and presented in other published work ${ }^{13}$.

Surface charges of Ag (AMPSA) NPs, GO QDs and PANI/Ag (AMPSA)/GO QDs. Zeta potential measurement is applied to determine the surface charge and consequently the stability of colloidal Ag (AMPSA) NPs, GO QDs and PANI/Ag (AMPSA)/GO QDs s as shown in Table 1. It is observed that the prepared nanomaterials have a negative surface charge. In addition, the zeta potential of the stable aqueous PANI/Ag (AMPSA)/ GO QDs NC is $-30.3 \mathrm{mV}$ and it is the most stable among the other nanomaterials. Colloids with zeta potential higher than $30 \mathrm{mV}$ (negative or positive) are stable ${ }^{22}$. According to the results obtained from Table 1, the stability of the synthesized materials colloidal decreases in the order of PANI/Ag (AMPSA)/GO QDs $>$ Ag (AMPSA) NPs $>$ GO QDs. 


\begin{tabular}{|l|l|}
\hline Specimen & Zeta potential $(\mathbf{m V})$ \\
\hline Ag (AMPSA) NPs & -26.9 \\
\hline GO QDs & -13.9 \\
\hline PANI/Ag (AMPSA)/GO QDs & -30.3 \\
\hline
\end{tabular}

Table 1. Zeta potential of the as-prepared aqueous NPs and NC.
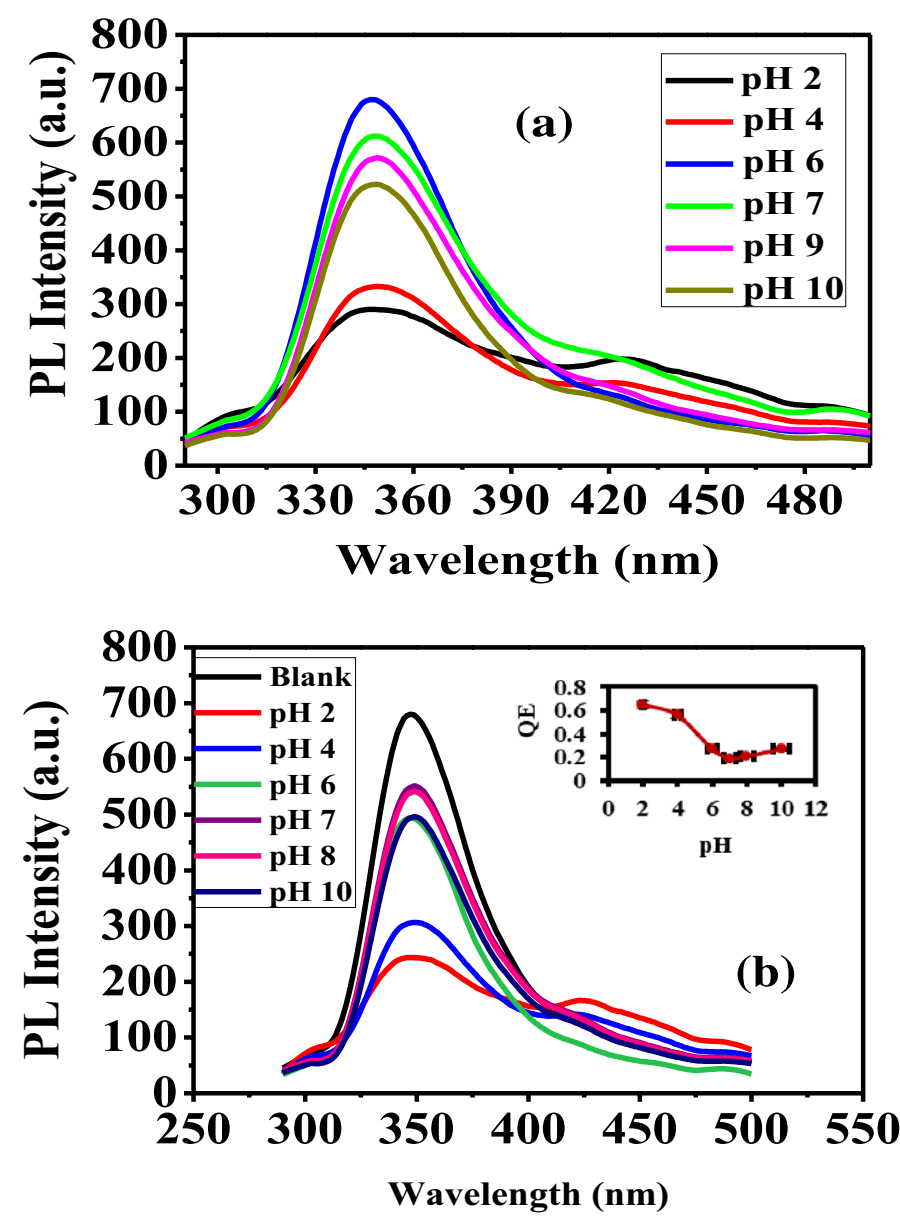

Figure 1. PL spectra of aqueous PANI/Ag (AMPSA)/GO QDs NC (a) in the absence and (b) in the presence of $0.5 \mathrm{mg} / \mathrm{L} \mathrm{Cr}(\mathrm{VI})$ at different $\mathrm{pHs}$, inset: $\mathrm{QE}$ versus $\mathrm{pH}$ at $\lambda \mathrm{ex}=270 \mathrm{~nm}$.

pH dependent fluorescence spectra of PANI/Ag (AMPSA)/GO QD NC. The effect of pH on both of the PL intensity and the quenching efficiency (QE) of PANI/Ag (AMPSA)/GO QDs in the absence and presence of $0.5 \mathrm{mg} / \mathrm{L} \mathrm{Cr}(\mathrm{VI})$ solution is investigated and carried out in the $\mathrm{pH}$ range from 2 to 10 as depicted in Fig. la,b. The PL intensity of PANI/Ag (AMPSA)/GO QD is improved in the range of $\mathrm{pH}$ from 2 to 6 . However, photoluminescence spectra is gradually declined again with further rising the $\mathrm{pH}$ from 6 to 10 as presented in Fig. 1a. This is can be explained based on the protonation and deprotonation of the amino groups at the PANI surface. It is proposed that the benzenoid rings are responsible for the fluorescence while at low $\mathrm{pH}$ the PANI is protonated and the conductive (quinoid rings) regions act as a fluorescence quencher ${ }^{23}$. Moreover, at low $\mathrm{pH}$ the aggregation of PANI/Ag (AMPSA)/GO QDs is manifested by the action of intramolecular hydrogen bond of the carboxylic acid moieties existed onto the surface of the PANI/Ag (AMPSA)/GO QDs ${ }^{24,25}$. On the other hand, PANI/Ag (AMPSA)/GO QDs is exhibited a new fluorescence band in the visible region $(427 \mathrm{~nm})$ at $\mathrm{pH} 2$ as a result of the formation of ground state species by electron donor-acceptor interaction between emeraldine salt and GO QDs or charge transfer interaction within the PANI-GO QDs ${ }^{26}$. Furthermore, at higher $\mathrm{pH}(7-10)$ deprotonation of amino groups of the PANI and carboxylic groups of GO QDs is generated negative charges on the surface and forms anionic double layers. This double layer disturbs the fluorescence spectra of the $\mathrm{NC}^{25}$.

Figure $1 \mathrm{~b}$ illustrates the effect of $\mathrm{pH}$ on the PL intensity and the QE of PANI/Ag (AMPSA)/GO QDs NC in the presence of $0.5 \mathrm{mg} / \mathrm{L} \mathrm{Cr}(\mathrm{VI})$. It is observed that the dependence of PL on the $\mathrm{pH}$ has the same trend in the 


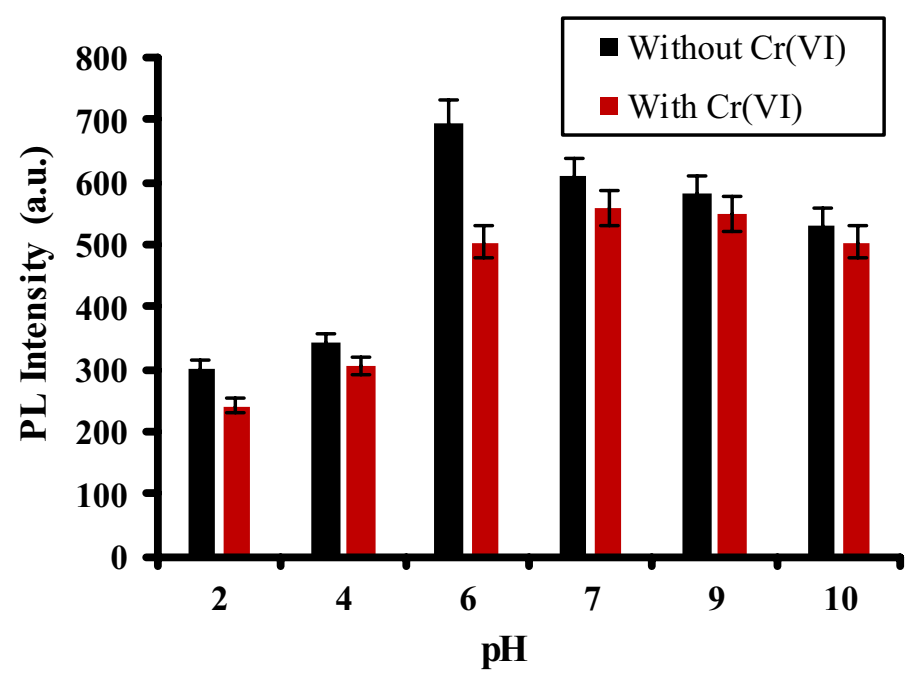

Figure 2. PL intensity of aqueous PANI/Ag (AMPSA)/GO QDs NC without and with $0.5 \mathrm{mg} / \mathrm{L} \mathrm{Cr}$ (VI) versus $\mathrm{pH}$ at $\lambda \mathrm{ex}=270 \mathrm{~nm}$.

absence of $\mathrm{Cr}(\mathrm{VI})$. However, the highest fluorescence is obtained at $\mathrm{pH}$ 7. The QE value of $\mathrm{Cr}(\mathrm{VI})$ is about $0.2-0.3$ at $\mathrm{pH}$ of $6-10$ and about $0.6-0.5$ at the $\mathrm{pH}$ of $2-4$. The higher $\mathrm{QE}$ at low $\mathrm{pH}$ is attributed to the low fluorescence intensity of the PANI/Ag (AMPSA)/GO QDs. The excitation energy exceeded the energy band gap is absorbed by PANI/Ag (AMPSA)/GO QDs and consequently the electrons are promoted from the valence band to the conduction band. These electrons are relaxed and returned again to their ground states by emission photons with longer wavelength ${ }^{27}$. It is found that the presence of $\mathrm{Cr}(\mathrm{VI})$ ions produces a quenching in the fluorescence of the PANI/Ag (AMPSA)/GO QDs.

Figure 2 compares between the PL intensity of PANI/Ag (AMPSA)/GO QDs in absence and presence of $0.5 \mathrm{mg} / \mathrm{L} \mathrm{Cr}(\mathrm{VI})$ at different pHs. The maximum PL intensity of PANI/Ag (AMPSA)/GO QDs without Cr(VI) is appeared at $\mathrm{pH}$ 6. It is noted that at this $\mathrm{pH}, \mathrm{QE}$ of $\mathrm{Cr}(\mathrm{VI})$ towards PANI/Ag (AMPSA)/GO QDs is optimal (about 0.3 ). Therefore, $\mathrm{pH} 6$ is chosen as the $\mathrm{pH}$ value for the detection of the $\mathrm{Cr}(\mathrm{VI})$ ions in the aqueous solution.

Interaction mechanism between PANI/Ag (AMPSA)/GO QDs and $\mathrm{Cr}(\mathrm{VI})$. Generally, the luminance quenching mechanisms by ions exchange of metal ions ${ }^{28}$, ligands competition and binding ${ }^{29}$, electron and energy transfer ${ }^{30,31}$, and inner filter process ${ }^{32}$ are possible to occur. The quenching processes of PANI/Ag (AMPSA)/GO QDs PL spectra by Cr(VI) ions are illustrated in Fig. 3a. Inner filter effect requests an overlap between the absorption spectrum of the absorber, the excitation spectrum and emission band of the QDs ${ }^{33}$. As shown in the inset in Fig. 3b, the UV-vis spectrum of $\mathrm{Cr}(\mathrm{VI})$ displays absorption peaks at 264 and $366 \mathrm{~nm}$. Figure $3 \mathrm{~b}$ depicts that PANI/Ag (AMPSA)/GO QDs NC exhibits high absorption band at $280 \mathrm{~nm}$, two shoulders at 345 and $425 \mathrm{~nm}$, and a broad band at $800 \mathrm{~nm}$, while strong emission peak at $348 \mathrm{~nm}$. The spectral overlap between the absorption peaks of $\mathrm{Cr}(\mathrm{VI})$ and the absorption and emission spectra of PANI/Ag (AMPSA)/GO QDs indicates the presence of filter effect. Moreover, the absorption spectra of $\mathrm{Cr}(\mathrm{VI})$ can be shielded part of the radiation for the excitation of the PANI/Ag (AMPSA)/GO QDs, as well as the Cr(VI) ions can absorb partially the emitted light by the PANI/Ag (AMPSA)/GO QDs. This supports also the inner filter effect between the $\mathrm{Cr}(\mathrm{VI})$ and the PANI/Ag (AMPSA)/GO QDs, and consequently reduces the intensity of fluorescence spectra ${ }^{18,20}$.

The zeta potential of the PANI/Ag (AMPSA)/GO QDs NC is demonstrated to be $-30.3 \mathrm{mV}$ (Table 1), and $\mathrm{Cr}(\mathrm{VI})$ is a negatively charged as monovalent bichromate $\mathrm{HCrO}_{4}{ }^{-}$under $\mathrm{pH}$ of $6-7^{34}$. Thus, a relatively long distance between PANI/Ag (AMPSA)/GO QDs and $\mathrm{Cr}(\mathrm{VI})$ is expected due to electrostatic repulsion ${ }^{20}$. However, it is observed that the maximum emission peak shifts from 348 to $336 \mathrm{~nm}$ (blue-shift) when PANI/Ag (AMPSA)/ GO QDs interact with $\mathrm{Cr}(\mathrm{VI})$ ions as will be shown in Fig. $5 \mathrm{a}$.

It has been reported that PANI could combine with $\mathrm{Cr}(\mathrm{VI})$ in an aqueous solution due to the ion exchange occurred between the dopant $\left(-\mathrm{SO}_{3}{ }^{-}\right)$and the negative $\mathrm{Cr}(\mathrm{VI})$ ions ${ }^{21}$. Also, the electron donating groups onto polyaniline structure $\left(-\mathrm{NH}_{2}\right)$ of the PANI/Ag (AMPSA)/GO QDs can strongly interact with metal ions to form the stable metal complexes ${ }^{35}$. These results suggesting that the quenching mechanism is not related only to inner filter effect process, but also the ground state compounds formation and ion exchange ${ }^{18,36}$.

Performance of PANI/Ag (AMPSA)/GO QDs for $\mathrm{Cr}(\mathrm{VI})$ detection. Upon addition of $5 \mathrm{mg} / \mathrm{L}$ of $\mathrm{Cr}(\mathrm{VI})$, the PL spectra and QE of PANI/Ag (AMPSA)/GO QDs NC are determined and plotted against the response time as demonstrated in Fig. 4a. The QE is reached equilibrium rapidly within approximately 2 min and then remained fixed (Fig. 4b). This reflects the high reactivity of PANI/Ag (AMPSA)/GO QDs towards Cr(VI) ions $^{37}$. Therefore, the proposed fluorescent sensor for $\mathrm{Cr}(\mathrm{VI})$ not only achieves rapid detection, but also exhibits high stability. 


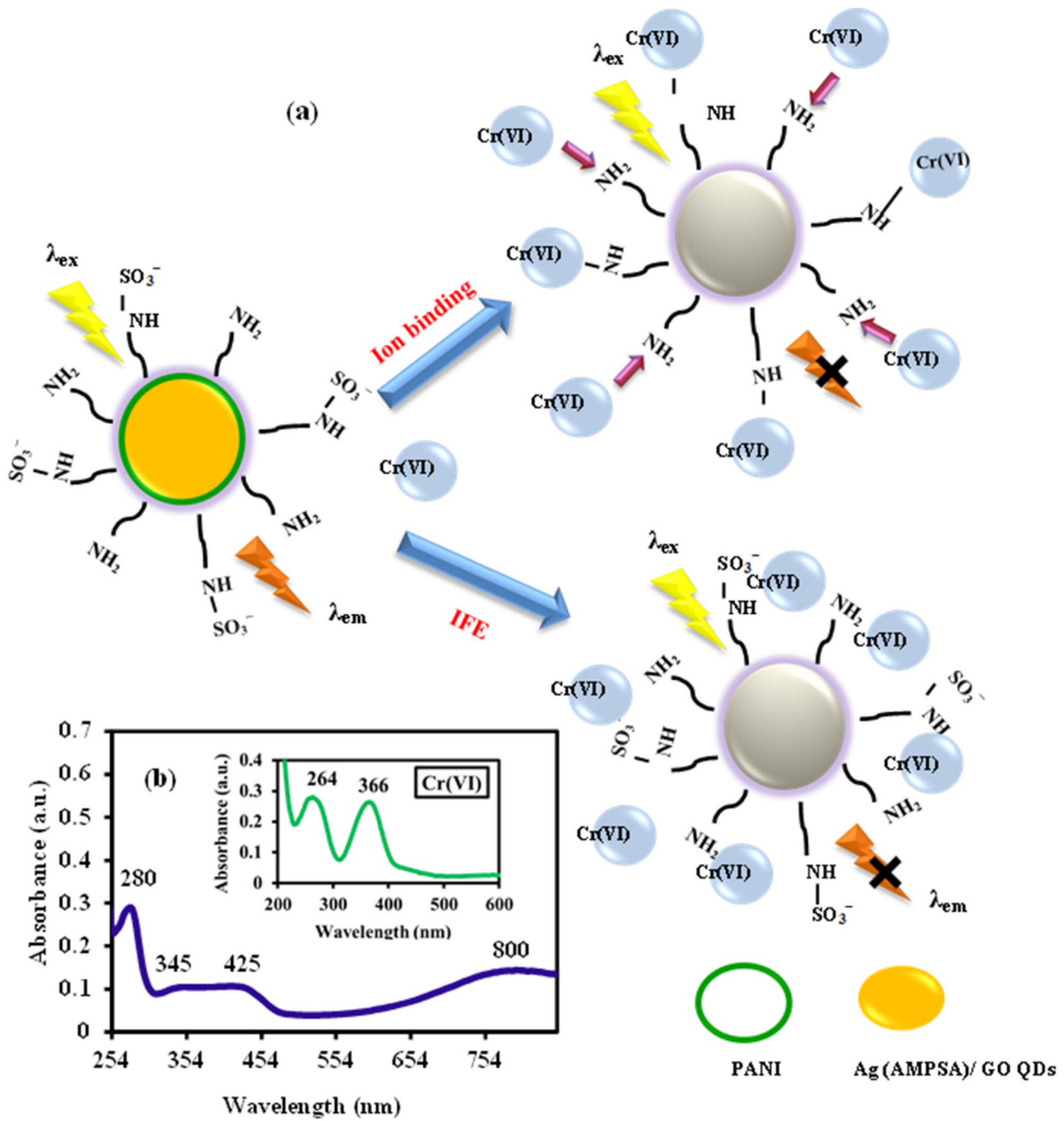

Figure 3. (a) Schematic illustration of the quenching processes of PANI/Ag (AMPSA)/GO QDs NC by Cr(VI) ions, $\lambda$ em is the emission wavelength and (b) UV-Vis spectra of PANI/Ag (AMPSA)/GO QDs NC and $5 \mathrm{mg} / \mathrm{L}$ $\mathrm{Cr}(\mathrm{VI})$ (the inset).

The linearity, sensitivity, dynamic range and the detection limit of PANI/Ag (AMPSA)/GO QDs sensor in the presence of series of concentrations of $\mathrm{Cr}(\mathrm{VI})(0-7.5 \mathrm{mg} / \mathrm{L})$ are determined using PL property. It is observed that by increasing concentration of $\mathrm{Cr}(\mathrm{VI})$, the PL intensity gradually decreases and a blue-shift of about $12 \mathrm{~nm}$ is noted as shown in Fig. 5a. This shift is an indication of a complex formation between $\mathrm{Cr}(\mathrm{VI})$ and PANI/Ag (AMPSA)/GO QDs NC ${ }^{18}$. The PL quenching efficiency of PANI/Ag (AMPSA)/GO QDs is related to Cr(VI) concentration as presented in inset of Fig. $5 \mathrm{~b}$.

There are two linear regions (dynamic range) of the correlation in the $\mathrm{Cr}(\mathrm{VI})$ concentration range of $0.01-0.05 \mathrm{mg} / \mathrm{L}\left(\mathrm{R}^{2}=0.9913\right)$ and $0.1-7.5 \mathrm{mg} / \mathrm{L}\left(\mathrm{R}^{2}=0.9982\right)$ as shown in Fig. $5 \mathrm{c}, \mathrm{d}$, respectively. This indicates that the quantitative determination of $\mathrm{Cr}(\mathrm{VI})$ using PANI/Ag (AMPSA)/GO QDs sensor can be performed with different sensitivities (slopes of the calibration lines) of 1.476 and $0.0981 \mathrm{~L} / \mathrm{mg}$ according to the range of detection. The detection limit obtained from the calibration line (Fig. $5 \mathrm{c})$ is $0.0065 \mathrm{mg} / \mathrm{L}(\sim 6 \mu \mathrm{g} / \mathrm{L})$ calculated from 

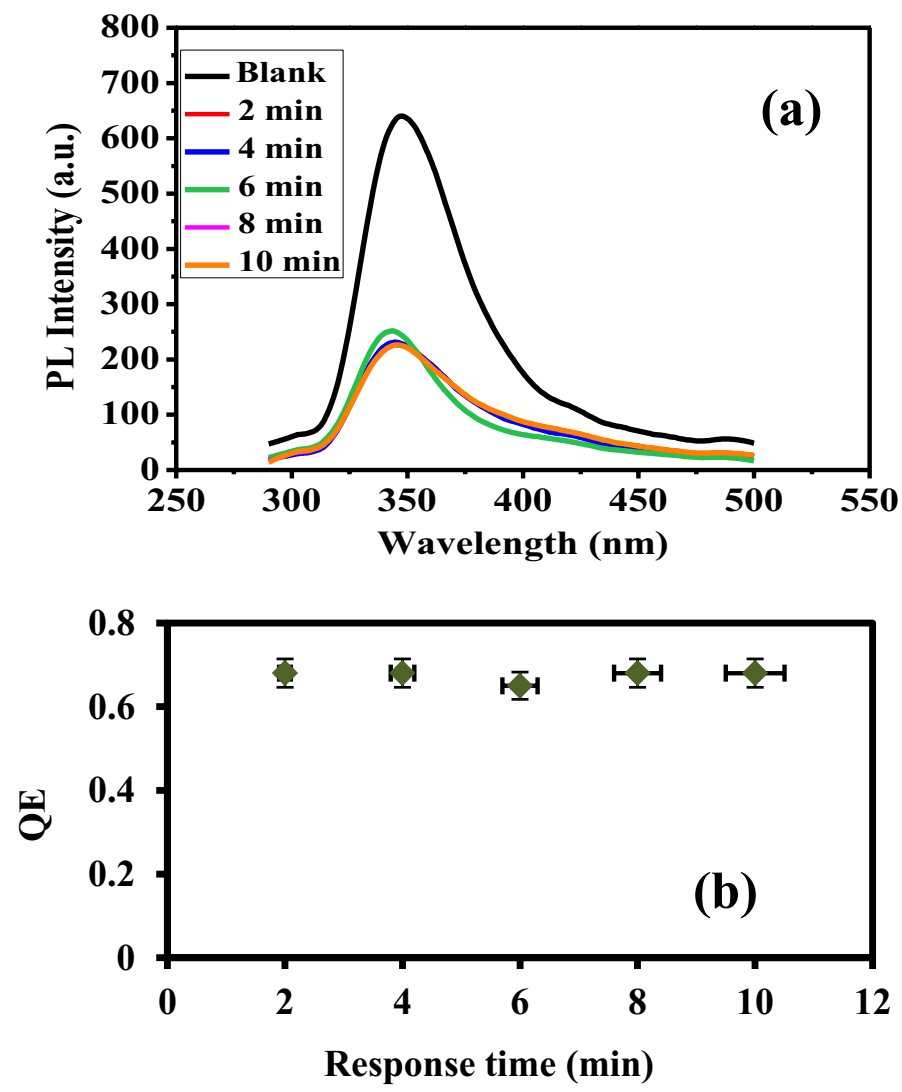

Figure 4. (a) PL intensity of PANI/Ag (AMPSA)/GO QDs in the presence of $5 \mathrm{mg} / \mathrm{L} \mathrm{Cr}(\mathrm{VI})$ at different times and (b) QE versus response time at $\mathrm{pH} 6$ and $\lambda \mathrm{ex}=270 \mathrm{~nm}$.

3SD/slope, where SD is the standard deviation and the slope of the calibration line. It is found that PANI/Ag (AMPSA)/GO QDs has a reasonable limit of detection for $\mathrm{Cr}(\mathrm{VI})$ ion in drinking water, which is lower than the maximum allowed limit of $50 \mu \mathrm{g} / \mathrm{L}$ set by the WHO. Therefore, PANI/Ag (AMPSA)/GO QDs based fluorescent sensor is sensitive enough to monitor $\mathrm{Cr}(\mathrm{VI})$ concentration in drinking water.

As listed in Table 2, the PANI/Ag (AMPSA)/GO QDs has low detection limit for Cr(VI) compared with other reported methods.

Stability, reproducibility and repeatability studies. The stability of PANI/Ag (AMPSA)/GO QDs was previously investigated ${ }^{13}$. The effect of ionic strength on the PL of PANI/Ag (AMPSA)/GO QDs NC was examined in the presence of different concentrations of $\mathrm{NaCl}$. Results revealed that up to the solution of $500 \mathrm{mM}$ $\mathrm{NaCl}$ has no significant effect on PL intensity due to the absence of interaction between the $\mathrm{NC}$ and $\mathrm{NaCl}$. Also, the PL intensity of PANI/Ag (AMPSA)/GO QDs NC was measured after stored at $30{ }^{\circ} \mathrm{C}$ for different periods. PANI/Ag (AMPSA)/GO QDs illustrated a high resistance to photobleaching and the fluorescence intensity was declined by $16.3 \%$ after five weeks.

The reproducibility of the NC sensor is estimated by measuring the PL intensity of five different NC samples added to $5 \mathrm{mg} / \mathrm{L} \mathrm{Cr}$ (VI) solutions prepared independently at $\mathrm{pH}$. The relative standard deviation (RSD) is calculated to be $3.9 \%$. Moreover, the repeatability of prepared NC is tested after 5 successive PL measurements of the same NC with $5 \mathrm{mg} / \mathrm{L} \mathrm{Cr}(\mathrm{VI})$ solution at $\mathrm{pH} 6$ and the RSD is found to be $2.4 \%$. These results confirm that the PANI/Ag (AMPSA)/ GO QDs NC sensor is highly reproducible and can be applied for repeatable measurements.

Selectivity and interferences of PANI/Ag (AMPSA)/GO QDs NC. Selectivity is a very important parameter to evaluate the performance of the fluorescent sensor. The selectivity of PANI/Ag (AMPSA)/GO QDs $\mathrm{NC}$ toward $\mathrm{Cr}(\mathrm{VI})$ is investigated by testing the PL variation and the change in the relative fluorescence intensity $\left(\mathrm{F} / \mathrm{F}_{0}\right)$ as shown in Fig. 6a,b in the presence of fixed concentration of $5 \mathrm{mg} / \mathrm{L}$ of different metal ions including $\mathrm{Cr}(\mathrm{VI}), \mathrm{Fe}(\mathrm{III}), \mathrm{Mg}(\mathrm{II}), \mathrm{Pb}(\mathrm{II}), \mathrm{Cu}(\mathrm{II}), \mathrm{Zn}(\mathrm{II}), \mathrm{K}(\mathrm{I}), \mathrm{Cd}(\mathrm{II}), \mathrm{Ni}(\mathrm{II}), \mathrm{Cr}(\mathrm{III}), \mathrm{Na}(\mathrm{I})$ and $\mathrm{Al}(\mathrm{III})$ at $\mathrm{pH} 6$ after incubation for $10 \mathrm{~min}$. It is observed that the enhancement of the fluorescence intensity of PANI/Ag (AMPSA)/GO QDs NC in the presence of some metal ions ( $\mathrm{Al}(\mathrm{III}), \mathrm{Cr}(\mathrm{III})$ and $\mathrm{K}(\mathrm{I})$ ) is attributed to chelation enhanced fluorescence effect ${ }^{43}$. Upon the interaction of $\mathrm{Cr}$ (III), $\mathrm{Al}$ (III) and $\mathrm{K}(\mathrm{I})$ ions with the PANI/Ag (AMPSA)/GO QDs, it is observed that a fluorescence enhancement has occurred. This PL enhancement is not due to structural factor. Rather it is attributed to the blocking or stabilization of the nitrogen lone pair orbital by metal coordination ${ }^{43,44}$. Moreover, as presented in Fig. 6a, two new small peaks at around 422 and $489 \mathrm{~nm}$ are observed suggesting the 

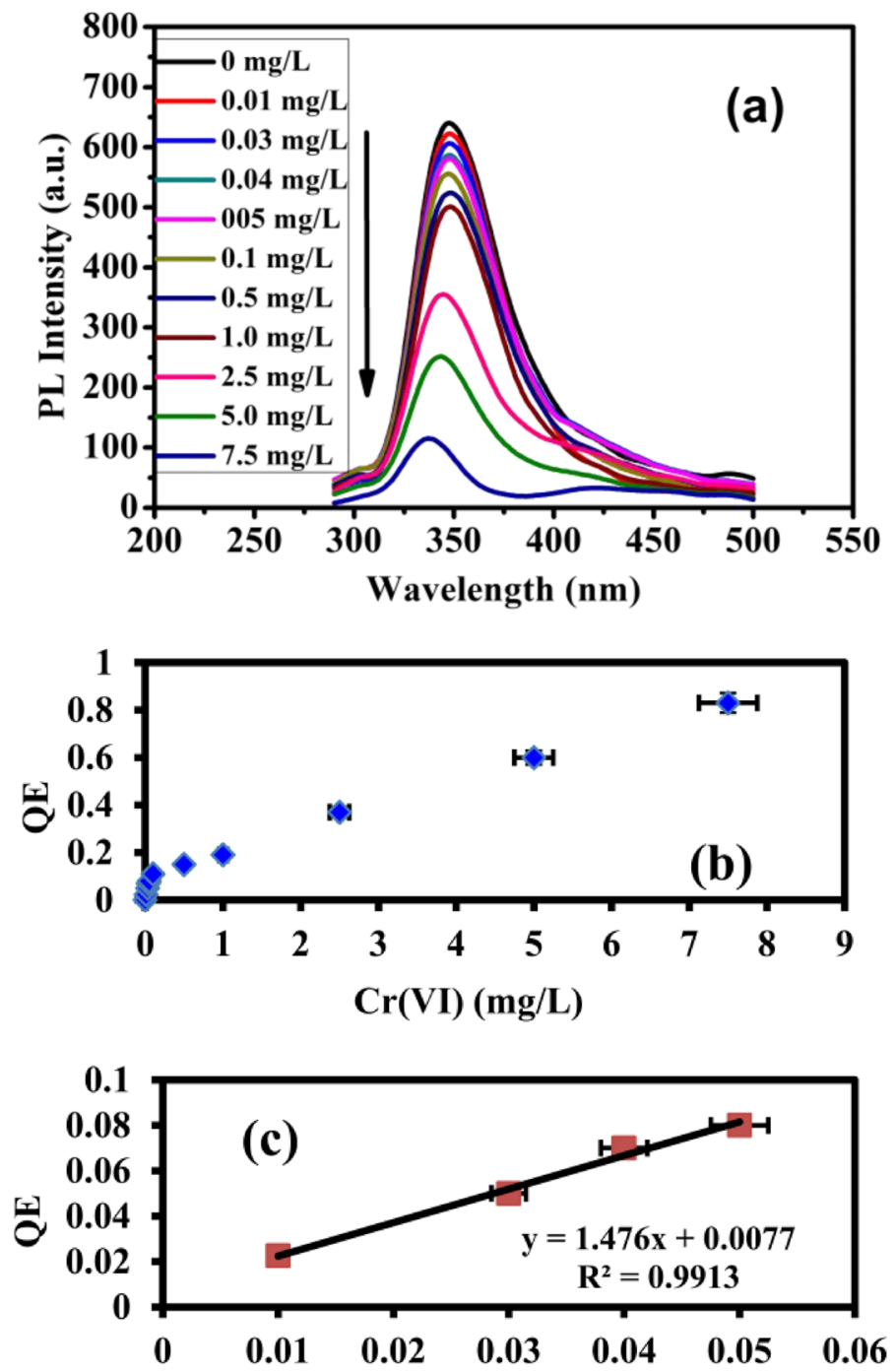

$\operatorname{Cr}(\mathrm{VI})(\mathrm{mg} / \mathrm{L})$

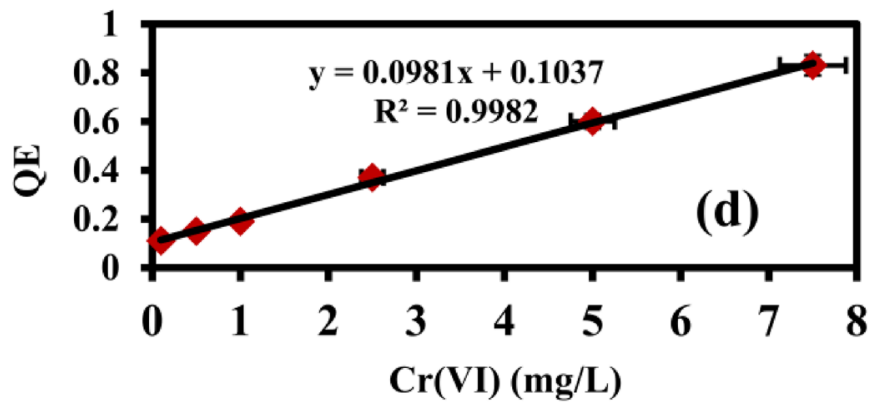

Figure 5. (a) PL spectra of PANI/Ag (AMPSA)/GO QDs with different concentrations of Cr(VI), (b) QE versus $\mathrm{Cr}(\mathrm{VI})$ concentration, (c) QE versus $\mathrm{Cr}(\mathrm{VI})$ concentration from 0.01 to $0.05 \mathrm{mg} / \mathrm{L}$ and (d) from 0.1 to $7.5 \mathrm{mg} / \mathrm{L}$ at $\mathrm{pH} 6$ and $\lambda \mathrm{ex}=270 \mathrm{~nm}$.

formation of $\mathrm{Cr}(\mathrm{III}), \mathrm{K}(\mathrm{I})$ or $\mathrm{Al}(\mathrm{III})$-ligand complex ${ }^{45}$. Consequently, PANI/Ag (AMPSA)/GO QDs have a potential application for monitoring $\mathrm{Cr}(\mathrm{III}), \mathrm{Al}(\mathrm{III})$ and $\mathrm{K}(\mathrm{I})$ in aqueous solutions.

It is also noted that $\mathrm{Cr}(\mathrm{VI})$ ions lead to a remarkable fluorescence quenching of PANI/Ag (AMPSA)/GO QDs whereas the other metal ions have a negligible quenching effect. To investigate the interference effect of different metals ions with $\mathrm{Cr}(\mathrm{VI}), \mathrm{Cr}(\mathrm{VI}) /$ mixed ions sample was prepared by mixing $5 \mathrm{mg} / \mathrm{L}$ of each ions with the PANI/ $\mathrm{Ag}$ (AMPSA)/GO QDs in presence of $5 \mathrm{mg} / \mathrm{L} \mathrm{Cr}(\mathrm{VI})$. The small change in the relative fluorescence intensity $\left(\mathrm{F} / \mathrm{F}_{0}\right)$ of the PANI/Ag (AMPSA)/GO QDs from 0.4 to 0.55 is occurred due to interfering ions compared to the 


\begin{tabular}{|l|l|l|l|l|}
\hline Sensor & Method & Linear range & LOD $(\mu \mathrm{g} / \mathrm{L})$ & Ref \\
\hline $\begin{array}{l}\text { Ion-imprinted polymers/Mn-doped } \\
\text { ZnS QDs }\end{array}$ & Fluorescent & $20-1.0 \mathrm{mg} / \mathrm{L}$ & 5.48 & 9 \\
\hline Carbon dots & Fluorescent & $0.10-12 \mu \mathrm{g} / \mathrm{mL}$ & 30.0 & 18 \\
\hline Glutathione/capped CdTe QDs & Fluorescent & $0.01-1.00 \mu \mathrm{g} / \mathrm{mL}$ & 8.0 & 38 \\
\hline GQD-modified membranes & Fluorescent & $52-26 \mathrm{mg} / \mathrm{L}$ & 9.9 & 39 \\
\hline Carbon dots & Fluorescent & $0.1-1 \mathrm{mg} / \mathrm{L}$ & 100.0 & 40 \\
\hline Phosphorus/carbon dots & Fluorescent & $52-20.8 \mathrm{mg} / \mathrm{L}$ & 12.5 & 41 \\
\hline $\begin{array}{l}\text { Zinc oxide quantum dot/ } \\
\text { colyvinylpyrrolidone/ quantum } \\
\text { carbon dots hydrogel composite }\end{array}$ & Fluorescent & $0-67.7 \mu \mathrm{g} / \mathrm{L}$ & 65.0 & 42 \\
\hline PANI/Ag (AMPSA)/GO QDs & Fluorescent & $\begin{array}{l}0.01-0.06 \mathrm{mg} / \mathrm{L} \\
0.1-7.5 \mathrm{mg} / \mathrm{L}\end{array}$ & 6.0 & This work \\
\hline
\end{tabular}

Table 2. Comparison of different methods for detecting $\mathrm{Cr}(\mathrm{VI})$. The permissible limit of $\mathrm{Cr}(\mathrm{VI})$ in drinking water set by $\mathrm{WHO}=50 \mu \mathrm{g} / \mathrm{L}$.
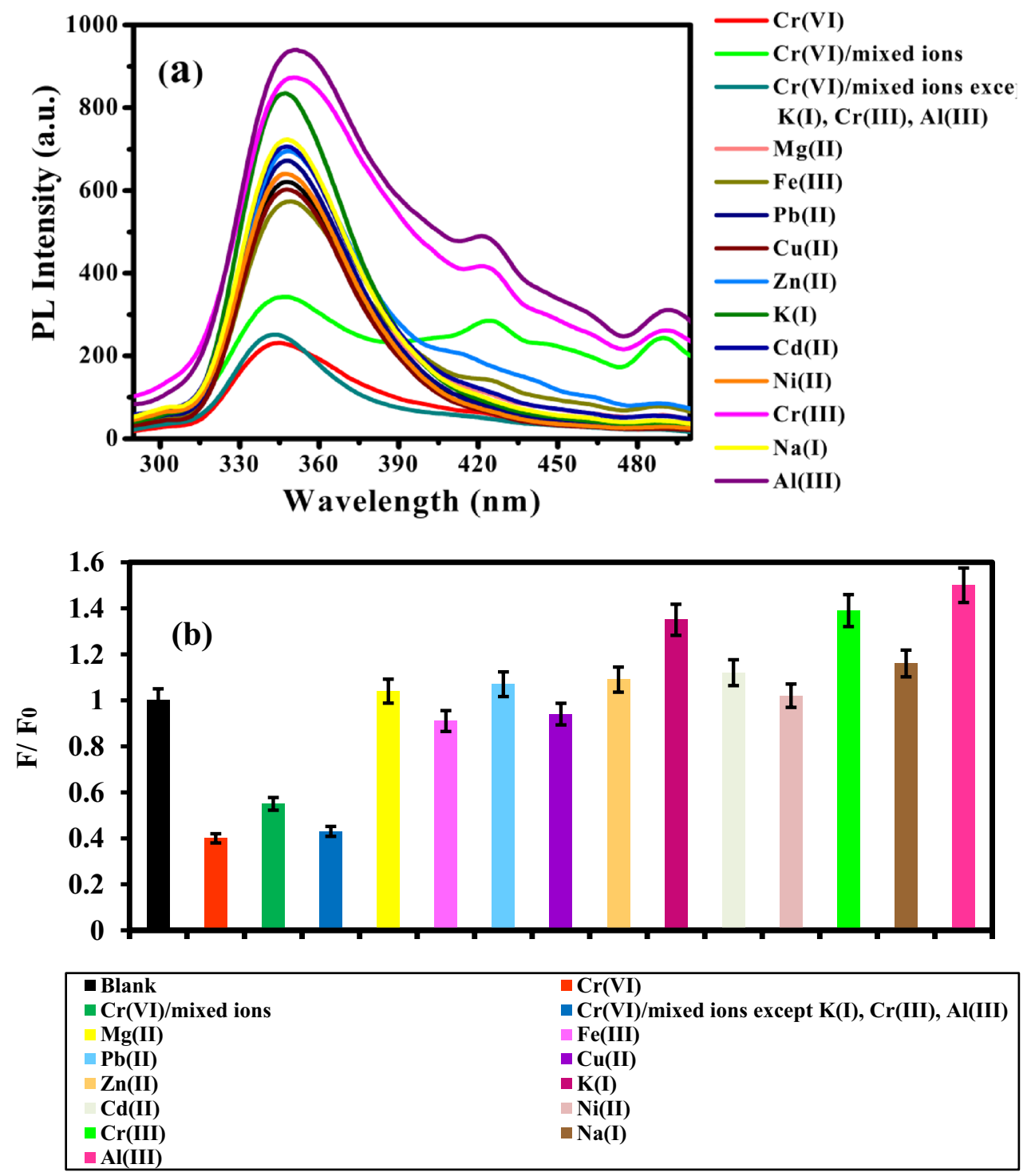

Figure 6. (a) PL intensity and (b) relative fluorescence intensity $\left(\mathrm{F} / \mathrm{F}_{0}\right)$ of PANI/Ag (AMPSA)/GO QDs versus $5 \mathrm{mg} / \mathrm{L}$ of different metal ions at $\mathrm{pH} 6, \lambda \mathrm{ex}=270 \mathrm{~nm}$. 


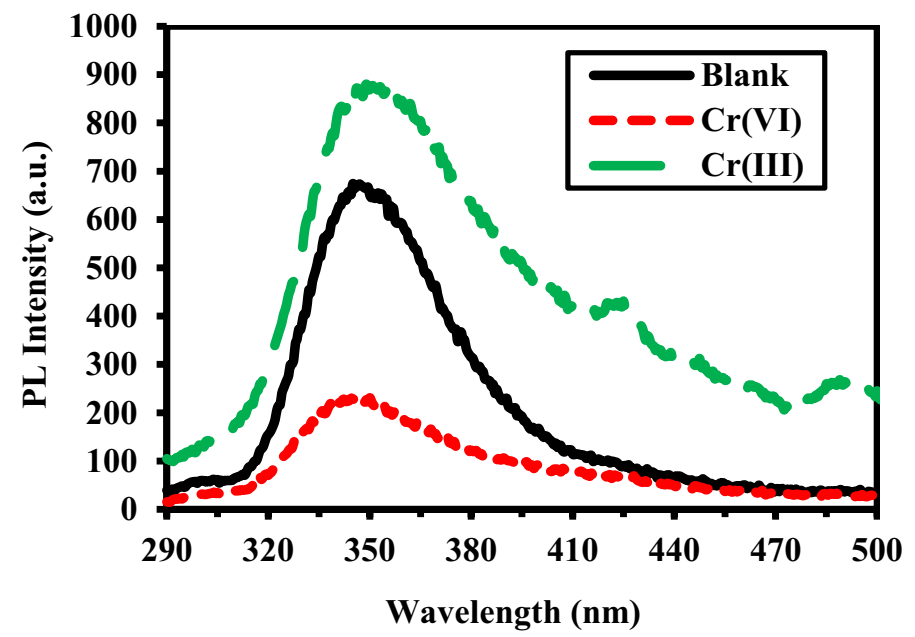

Figure 7. PL intensity of PANI/Ag (AMPSA)/GO QDs versus $5 \mathrm{mg} / \mathrm{L}$ of $\mathrm{Cr}(\mathrm{VI})$ and $\mathrm{Cr}(\mathrm{III})$ at $\mathrm{pH}$, $\lambda \mathrm{ex}=270 \mathrm{~nm}$.

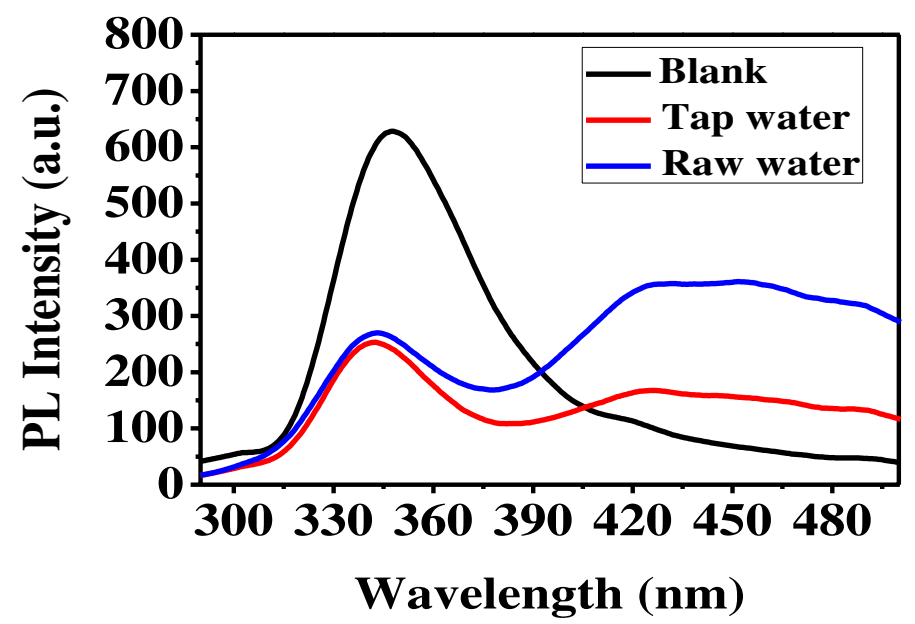

Figure 8. PL intensity of PANI/Ag (AMPSA)/GO QDs in local tap and raw water samples spiked with $5 \mathrm{mg} / \mathrm{L}$ $\mathrm{Cr}(\mathrm{VI})$ at $\mathrm{pH} 6, \lambda \mathrm{ex}=270 \mathrm{~nm}$.

one of the sample contains only $\mathrm{Cr}(\mathrm{VI})$ in deionized water from 0.4 to 0.55 (Fig. $6 \mathrm{~b}$ ). We also carried out this experiment of $\mathrm{Cr}(\mathrm{VI})$ /mixed ions in the absence of $\mathrm{Cr}(\mathrm{III}), \mathrm{Al}(\mathrm{III})$ and $\mathrm{K}(\mathrm{I})$ as shown in Fig. 6a,b. The PL intensity of this mixture is almost similar to the PL of the solution contains only $\mathrm{Cr}(\mathrm{VI})$ ions. These results revealed that the $\mathrm{Cr}(\mathrm{VI}) /$ mixed ions sample that contains all metal ions has lesser quenching than the sample involves only $\mathrm{Cr}(\mathrm{VI})$ due to the presence of $\mathrm{Cr}(\mathrm{III}), \mathrm{Al}(\mathrm{III})$ and $\mathrm{K}(\mathrm{I})$ ions which enhance the PL.

These results confirm that PANI/Ag (AMPSA)/GO QDs sensor is successfully able to discriminate between the two oxidation states of chromium ions (Fig. 7) where $\mathrm{Cr}(\mathrm{VI})$ quenches the PL and Cr(III) enhances the PL.

Determination of $\mathrm{Cr}(\mathrm{VI})$ in water samples. In order to validate this proposed nanocomposite and method, two local water samples spiked with $5 \mathrm{mg} / \mathrm{L} \mathrm{Cr}(\mathrm{VI})$ was determined. The PL spectra of these two water samples are measured as shown in Fig. 8 from which the $\mathrm{Cr}(\mathrm{VI})$ concentrations were determined using the calibration curve in Fig. 5d. The $\mathrm{Cr}(\mathrm{VI})$ concentrations determined by the PANI/Ag (AMPSA)/GO QDs sensor are almost the same as those determined by the standard DFC method $(5 \mathrm{mg} / \mathrm{L})$.

The recoveries are estimated by measuring the PL intensities of five different tap water and raw water samples, each sample includes $5 \mathrm{mg} / \mathrm{L} \mathrm{Cr}(\mathrm{VI})$ prepared independently at $\mathrm{pH}$ 6. It is found that the recoveries are in the range of $95.3-99.2 \%$ as shown in Table 3. The RSD is calculated to be $4.1 \%$ and $4.2 \%$ for tap water and raw water. It can be concluded that PANI/Ag (AMPS)/GO QDs sensor has a promising potential for monitoring $\mathrm{Cr}(\mathrm{VI})$ in water. 


\begin{tabular}{|l|l|l|l|l|l|}
\hline Sample & $\mathbf{C r}(\mathbf{V I})(\mathbf{m g} / \mathbf{L})$ & $\mathbf{C r}(\mathbf{V I})$ added $(\mathbf{m g} / \mathbf{L})$ & $\mathbf{C r}(\mathbf{V I})$ found $(\mathbf{m g} / \mathbf{L})$ & Recovery $(\%)$ & RSD $(\%)$ \\
\hline Tap water & N.D & 5 & 4.96 & 99.2 & 4.1 \\
\hline Raw water & N.D & 5 & 4.75 & 95.3 & 4.2 \\
\hline
\end{tabular}

Table 3. The measured and recovered of $\mathrm{Cr}(\mathrm{VI})$ ions in the two water samples. ND, not detected. Recovery $\%=($ concentration found $/$ concentration spiked $) \times 100 \%$.

\section{Conclusion}

In summary, PANI/Ag (AMPSA)/GO QDs NC was used as a sensitive fluorescence quenching probe for detecting $\mathrm{Cr}(\mathrm{VI})$ successfully. This probe possessed a low detection limit of $6 \mu \mathrm{g} / \mathrm{L}$ which is lower than the WHO standard permitted limit for $\mathrm{Cr}(\mathrm{VI})$ in drinking water $(50 \mu \mathrm{g} / \mathrm{L})$. Furthermore, the PANI/Ag (AMPSA)/GO QDs NC sensor offered several advantages such as good selectivity, fast response time, and high stability, reproducibility and repeatability. The mechanism of quenching is possibly due to the synergistic effect of inner filter effect, the ground state compounds formation and ion exchange. Moreover, PANI/Ag (AMPSA)/GO QDs NC have a potential application for monitoring $\mathrm{Cr}(\mathrm{III}), \mathrm{Al}(\mathrm{III})$ and $\mathrm{K}(\mathrm{I})$ in aqueous solutions. The real applicability of the sensor was also tested by analyzing real water samples spiked with known concentration of $\mathrm{Cr}(\mathrm{VI})$ and satisfactory recovery of $\mathrm{Cr}(\mathrm{VI})$ was obtained. We believe that this proposed fluorescent sensor possesses high potentials in the recognition of $\mathrm{Cr}(\mathrm{VI})$ in real water samples.

Received: 16 June 2020; Accepted: 3 August 2020

Published online: 12 August 2020

\section{References}

1. Shokry, A., El-Tahan, A., Ibrahim, H., Soliman, M. \& Ebrahim, S. Polyaniline/akaganéite superparamagnetic nanocomposite for cadmium uptake from polluted water. Desalin. Water Treat. 171, 205-215 (2019).

2. Coetzee, J. J., Bansal, N. \& Chirwa, E. M. N. Chromium in environment, its toxic effect from chromite-mining and ferrochrome industries, and its possible bioremediation. Expo. Health 12, 51-62 (2020).

3. WHO. Chromium in drinking-water. Background document for preparation of WHO Guidelines for drinking-water quality. Geneva, (WHO/SDE/WSH/03.04/4) (2003).

4. Miyake, Y. et al. Determination of hexavalent chromium concentration in industrial waste incinerator stack gas by using a modified ion chromatography with post-column derivatization method. J. Chromatogr. A 1502, 24-29 (2017).

5. Drinčić, A., Zuliani, T., Ščančar, J. \& Milačič, R. Determination of hexavalent $\mathrm{Cr}$ in river sediments by speciated isotope dilution inductively coupled plasma mass spectrometry. Sci. Total Environ. 637-638, 1286-1294 (2018).

6. Jiang, H., Yang, T., Wang, Y., Lian, H. \& Hu, X. Magnetic solid-phase extraction combined with graphite furnace atomic absorption spectrometry for speciation of $\mathrm{Cr}(\mathrm{III})$ and $\mathrm{Cr}$ (VI)in environmental waters. Talanta 116, 361-367 (2013).

7. Ma, J., Wang, Z., Li, Q., Gai, R. \& Li, X. On-line separation and preconcentration of hexavalent chromium on a novel mesoporous silica adsorbent with determination by solution-cathode glow discharge-atomic emission spectrometry. J. Anal. At. Spectrom. 29, 2315-2322 (2014).

8. Eaton, A., Ramirez, L. M. \& Haghani, A. The erinbrockovich factor-analysis of total and hexavalent chromium in drinking waters. In American water works association water quality and technology conference procedings, Nashville, TN. (2001).

9. Zhang, M. Y. et al. Selective fluorescence sensor based on ion-imprinted polymer-modified quantum dots for trace detection of $\mathrm{Cr}(\mathrm{VI})$ in aqueous solution. Anal. Bioanal. Chem. 411, 7165-7175 (2019).

10. Su, Y., Wang, Y., Li, X., Li, X. \& Wang, R. Imidazolium-based porous organic polymers: anion exchange-driven capture and luminescent probe of $\mathrm{Cr}_{2} \mathrm{O}_{7}{ }^{2-}$. ACS Appl. Mater. Interfaces 8, 18904-18911 (2016).

11. Lin, Y.-S., Chiu, T.-C. \& Hu, C.-C. Fluorescence-tunable copper nanoclusters and their application in hexavalent chromium sensing. RSC Adv. 9, 9228-9234 (2019).

12. Mutuyimana, F. P. et al. Yellow-emissive carbon dots as a fluorescent probe for chromium(VI). Microchim. Acta 3, 186-194 (2019).

13. Shokry, A., Khalil, M. M. A., Ibrahim, H., Soliman, M. \& Ebrahim, S. Highly luminescent ternary nanocomposite of polyaniline, silver nanoparticles and graphene oxide quantum dots. Sci. Rep. 9, 16984-16995 (2019).

14. Devi, N. R., Sasidharan, M. \& Sundramoorthy, A. K. Gold nanoparticles-thiol-functionalized reduced graphene oxide coated electrochemical sensor system for selective detection of mercury ion. J. Electrochem. Soc. 165, 3046-3053 (2018).

15. Govindasamy, M., Mani, V., Chen, S.-M., Chen, T.-W. \& Sundramoorthy, A. K. Methyl parathion detection in vegetables and fruits using silver@graphene nanoribbons nanocomposite modified screen printed electrode. Sci. Rep. 7, 46471-46481 (2017).

16. Sharma, V., Sundaramurthy, A., Tiwari, A. \& Sundramoorthy, A. K. Graphene nanoplatelets-silver nanorods-polymer based in-situ hybrid electrode for electroanalysis of dopamine and ascorbic acid in biological samples. Appl. Surf. Sci. 449, 558-566 (2018).

17. Murugan, N., Murugan, C. \& Sundramoorthy, A. K. In vitro and in vivo characterization of mineralized hydroxyapatite/polycaprolactone-graphene oxide based bioactive multifunctional coating on Ti alloy for bone implant applications. Arab. J. Chem. 11, 959-969 (2018).

18. Vaz, R. et al. High luminescent carbon dots as an eco-friendly fluorescence sensor for $\mathrm{Cr}(\mathrm{VI})$ determination in water and soil samples. J. Photochem. Photobiol. A Chem. 346, 502-511 (2017).

19. Shehab, M., Ebrahim, S. \& Soliman, M. Graphene quantum dots prepared from glucose as optical sensor for glucose. J. Lumin. 184, 110-116 (2017).

20. Li, P., Hong, Y., Feng, H. \& Li, S. F. Y. An efficient “"off-on"” carbon nanoparticle-based fluorescent sensor for recognition of chromium(VI) and ascorbic acid based on the inner filter effect. J. Mater. Chem. B 5, 2979-2988 (2017).

21. Ebrahim, S., Shokry, A., Ibrahim, H. \& Soliman, M. Polyaniline/akaganéite nanocomposite for detoxification of noxious $\mathrm{Cr}(\mathrm{VI})$ from aquatic environment. J. Polym. Res. 23, 79-90 (2016).

22. Everett, D. H. Basic principles of colloid science (RSC, London, 1988).

23. Santos, R. F. S., Andrade, C. A. S., Santos, C. G. \& Melo, C. P. Visible luminescence in polyaniline/(gold nanoparticle) composites. J. Nanoparticle Res. 15, 1408-1418 (2013).

24. Amjadi, M., Shokri, R. \& Hallaj, T. A new turn-off fluorescence probe based on graphene quantum dots for detection of $\mathrm{Au}(\mathrm{III})$ ion. Spectrochim. Acta A Mol. Biomol. Spectrosc. 153, 619-624 (2016).

25. Sharma, S., Mehta, S. K. \& Kansal, K. Highly fluorescent silver oxide/C-dots nanocomposite as selective and sensitive probe for highly efficient detection of Fe(III) ions. Sens. Actuators B Chem. 243, 1148-1156 (2017). 
26. Saha, P. et al. A pH dependent tunable photoluminescence of polyaniline grafted graphene oxide (GO-PANI) nanocomposite. J. Lumin. 181, 138-146 (2017).

27. Callis, P. R. Binding phenomena and fluorescence quenching. I: descriptive quantum principles of fluorescence quenching using a supermolecule approach. J. Mol. Struct. 1077, 14-21 (2014).

28. Kacmaz, S. et al. An ultra-sensitive fluorescent nanosensor for detection of ionic copper. Spectrochim. Acta A Mol. Biomol. Spectrosc. 135, 551-559 (2015)

29. Wang, X., Lv, Y. \& Hou, X. A potential visual fluorescence probe for ultratrace arsenic (III) detection by using glutathione-capped CdTe quantum dots. Talanta 84, 382-386 (2011).

30. Zhang, Q., Sun, Y., Liu, M. \& Liu, Y. Selective detection of $\mathrm{Fe}^{3+}$ ions based on fluorescence MXene quantum dots via a mechanism integrating electron transfer and inner filter effect. Nanoscale 12, 1826-1832 (2020).

31. Yu, J. et al. Green preparation of carbon dots by Jinhua bergamot for sensitive and selective fluorescent detection of $\mathrm{Hg}^{2+}$ and $\mathrm{Fe}^{3+}$. Sens. Actuators B Chem. 214, 29-35 (2015).

32. Pal, S., Roy, D., Bar, N., Chowdhury, S. \& Chowdhury, P. Polyaniline as an On-Off-On bright green fluorescent probe: solvent directed synthesis, characterization and recognition of chromium through the inner filter effect. Polymer 191, 122292 (2020).

33. Liu, Y. et al. Carbon-based dots co-doped with nitrogen and sulfur for $\mathrm{Cr}(\mathrm{VI})$ sensing and bioimaging. RSC Adv. 6, 28477-28483 (2016).

34. Pourbaix, M. Atlas of electrochemical equilibria in aqueous solutions. NACE TX, 2nd edition, Houston 257-260 (1974).

35. Song, X., Sun, H., Yang, S., Zhao, S. \& Liao, F. Synthesis of photoluminescent o-phenylenediamine-m-phenylenediamine copolymer nanospheres: an effective fluorescent sensing platform for selective and sensitive detection of chromium(VI) ion. J. Lumin. 169, $186-190$ (2016).

36. $\mathrm{Xu}$, Y. et al. Adsorptive stripping voltammetry determination of hexavalent chromium by a pyridine functionalized gold nanoparticles/three-dimensional graphene electrode. Microchem. J. 149, 104022 (2019).

37. Huang, S., Qiu, H., Zhu, F., Lu, S. \& Xiao, Q. Graphene quantum dots as on-off-on fluorescent probes for chromium(VI) and ascorbic acid. Microchim. Acta 182, 1723-1731 (2015).

38. Zhang, L., Xu, C. \& Li, B. Simple and sensitive detection method for chromium(VI) in water using glutathione-capped CdTe quantum dots as fluorescent probes. Microchim. Acta 166, 61-68 (2009).

39. Carrasco, P. M. et al. Graphene quantum dot membranes as fluorescent sensing platforms for Cr(VI) detection. Carbon 109, 658-665 (2016).

40. Roshni, V., Misra, S., Santra, M. K. \& Ottoor, D. One pot green synthesis of C-dots from groundnuts and its application as $\mathrm{Cr}(\mathrm{VI})$ sensor and in vitro bioimaging agent. J. Photochem. Photobiol. A Chem. 373, 28-36 (2019).

41. $\mathrm{Bu}, \mathrm{L}$. L. et al. Fluorescent carbon dots for the sensitive detection of $\mathrm{Cr}(\mathrm{VI})$ in aqueous media and their application in test papers. RCS Adv. 6, 95469-95475 (2016).

42. Truskewycz, A., Beker, S. A., Ball, A. S., Murdoch, B. \& Cole, I. Incorporation of quantum carbon dots into a zinc oxide hydrogel for use as an effective hexavalent chromium sensing platform. Anal. Chim. Acta 1099, 126-135 (2020).

43. Faraz, M. et al. Polyindole/cadmium sulphide nanocomposite based turn-on, multi-ion fluorescence sensor for detection of $\mathrm{Cr}^{3+}$, $\mathrm{Fe}^{3+}$ and $\mathrm{Sn}^{2+}$ ions. Sens. Actuators B Chem. 269, 195-202 (2018).

44. Afaneh, A. T. \& Schreckenbach, G. Fluorescence enhancement/quenching based on metal orbital control: computational studies of a 6-Thienyllumazine-based mercury sensor. J. Phys. Chem. A 119, 8106-8116 (2015).

45. Wu, S., Dai, X., Cheng, T. \& Li, S. Highly sensitive and selective ion-imprinted polymers based on one-step electrodeposition of chitosan-graphene nanocomposites for the determination of Cr(VI). Carbohydr. Polym. 195, 199-206 (2018).

\section{Author contributions}

S.E. and A.S. contributed to ideas, experiment execution and interpretation of the data and writing of the manuscript. M.M.A.K. and H.I. share in the characterization of the prepared nanocomposite and explaining the results of characterization. M.S. supervised the experiments and wrote and edited the manuscript.

\section{Competing interests}

The authors declare no competing financial interests.

\section{Additional information}

Correspondence and requests for materials should be addressed to A.S.

Reprints and permissions information is available at www.nature.com/reprints.

Publisher's note Springer Nature remains neutral with regard to jurisdictional claims in published maps and institutional affiliations.

Open Access This article is licensed under a Creative Commons Attribution 4.0 International License, which permits use, sharing, adaptation, distribution and reproduction in any medium or
format, as long as you give appropriate credit to the original author(s) and the source, provide a link to the Creative Commons license, and indicate if changes were made. The images or other third party material in this article are included in the article's Creative Commons license, unless indicated otherwise in a credit line to the material. If material is not included in the article's Creative Commons license and your intended use is not permitted by statutory regulation or exceeds the permitted use, you will need to obtain permission directly from the copyright holder. To view a copy of this license, visit http://creativecommons.org/licenses/by/4.0/.

(C) The Author(s) 2020 